information in this book may not always be convincing or devoid of ambiguity, but these faults are the faults of the quality of the work.

Still if the monograph is as good as it can be on the pathological side it is disappointing in its main object-that of supplying guidance on the treatment of headaches. The treatment of the symptomatic headache is obvious enough, but it is a fact that most headaches have no clear association with any gross disturbance, and on this subject the author appears to have but little to say. He does not seem to have learnt the lesson that Weir Mitchell taught on the relationship of eyestrain and headaches. The eye is indeed discussed as one of the possible sources of headaches, but in agreement with the whole plan of the book pride of place is given to gross organic lesions like glaucoma and iritis. Heterophoria is discussed but refractive errors are dismissed in two sentences. A good account of migraine is marred by the omission of any reference to the eye as the possible source of trouble. From the point of view of treatment these are by no means minor faults. Cooperation with an oculist would have made the author's work more balanced, and incidentally he would have learnt not to attempt to diagnose acute glaucoma from fundus appearances.

\title{
CORRESPONDENCE
}

To the Editor of The British Journal of Ophthalmology.

SIR,-While engaged recently in making an English translation of the De Oculis of Benevenutus Grassus, the first printed monograph on the eye and its diseases (Ferrard 1474), I tried to locate all existing copies of that extremely rare little book.

Three copies in America and four in Continental Europe completed the census so far taken, but it seemed to me that there must $b e$ others, especially in Great Britain, whence came two of our examples. Aided by Mr. R. R. James and Dr. Charles Singer, I sent a questionnaire to the principal libraries of this country, but without result. Quite recently, however, I received a note from Mr. S. Wood, Library Assistant of the Royal College of Surgeons, informing me that there is a copy on the shelves of their library.

Through the courtesy of the officials I have been able to collate the volume, and was much pleased to note that it is a fine copy in a good state of preservation-an exact replica of each of the American trio. It is Pinelli's own copy, having been listed in his catalogue, and there are annotations copied on the recto of the first blank leaf. Neither the initials nor lines are rubricated but there are many marginal notes in red ink. It was purchased for the 
College Library at the Riggal's Library sale in 1902, thus making the eighth of the known copies of the work.

Mr. Wood drew my attention to a reference previously unknown to me, a "Review of the First Book on Diseases of the Eye by Benevenutus Grassus," by Fred. P. Henry, Hon Librarian of the College of Physicians, Philadelphia, published in the Med. Library and Histor. Journal, New York, 1909, p.29, in which a brief history of this remarkable treatise is correctly given.

\section{Yours truly,}

LONDON,

Casey A. Wood.

July 12, 1929.

\section{NOTES}

WE regret to record the death of Hugh Campbell Death Highet, M.D., D.P.H., on July 29, 1929. Born in 1866, and educated in Scotland, most of his professional career was spent in the Far East, where he held appointments in Siam and Bangkok. He retired from Siam in 1919 and settled in Winchester, where he rapidly achieved success as an ophthalmic surgeon.

Presentation to Dr. Ernst Fuchs

New York City, July 29. In recognition of " the most outstanding achievement in the prevention of blindness and the conservation of vision," Dr. Ernst Fuchs, of Vienna, will be awarded the Leslie Dana Gold Medal. The presentation will be made at the International Ophthalmological Congress in Amsterdam, Holland, September 10, by Dr. William H. Luedde, of St. Louis, director of the Prevention of Blindness Department of the Missouri Association for the Blind, through which the medal is offered annually by Mr. Leslie Dana, also of St. Louis.

" In selecting Dr. Fuchs, there was a departure for the first time from the usual custom of considering only Americans for this honour," said Mr. Carris, Director of the National Society for the Prevention of Blindness of New York. "Dr. Fuchs charted the way for all prevention of blindness work accomplished throughout the world in the last 45 years; he did this when he won the prize at the Fifth International Congress for Hygiene at the Hague in 1884 with his essay on 'The Causes and Prevention of Blindness.' Dr. Fuchs was a professor of ophthalmology in the University of Liège at that time; he has been distinguished in his profession for more than half a century." 